\title{
Prevalence of common canine digestive problems compared with other health problems in teaching veterinary hospital, Faculty of Veterinary Medicine, Cairo University, Egypt
}

\author{
Gamal M. H. Rakha ${ }^{1}$, Mounir M. Abdl-Haleem ${ }^{1}$, Haithem A. M. Farghali², and Hitham Abdel-Saeed ${ }^{1}$
}

1. Department of Internal Medicine and Infectious Diseases, Faculty of Veterinary Medicine, Cairo University, Giza, Egypt; 2. Department of Surgery, Faculty of Veterinary Medicine, Cairo University, Giza, Egypt.

Corresponding author: Hitham Abdel-Saeed, e-mail: Dr.hysam2013@yahoo.com, GMHR: gmlrakha@yahoo.com, MMA: Mounir_12344@hotmail.com, HAMF: dr_haithemo@yahoo.com

Received: 03-11-2014, Revised: 11-02-2015, Accepted: 17-02-2015, Published online: 26-03-2015

doi: 10.14202/vetworld.2015.403-411. How to cite this article: Rakha GMH, Abdl-Haleem MM, Farghali HAM, Abdel-Saeed H (2015) Prevalence of common canine digestive problems compared with other health problems at teaching veterinary hospital, Faculty of Veterinary Medicine, Cairo University, Egypt, Veterinary World 8(3):403-411.

\begin{abstract}
Aim: The present study was conducted to ascertain the prevalence of common digestive problems compared to other health problems among dogs that were admitted to the teaching veterinary hospital, faculty of veterinary medicine, Cairo University, Egypt during 1 year period from January to December 2013. Also, study the effect of age, sex, breeds, and season on the distribution of digestive problems in dogs.

Materials and Methods: A total of 3864 dogs included 1488 apparently healthy (included 816 males and 672 females) and 2376 diseased dogs (included 1542 males and 834 females) were registered for age, sex, breed, and the main complaint from their owners. A complete history and detailed clinical examination of each case were applied to the aids of radiographic, ultrasonographic, and endoscopic examination tools. Fecal examination was applied for each admitted case. Rapid tests for parvovirus and canine distemper virus detection were also performed.

Results: A five digestive problems were commonly recorded including vomiting, diarrhea, concurrent vomiting with diarrhea, anorexia, and constipation with a prevalence $(\%)$ of 13.6, 19.1, 10.1, 13.1, and 0.5 respectively while that of dermatological, respiratory, urinary, neurological, cardiovascular, auditory, and ocular problems was 27.9, 10.5, 3.3, 0.84, $0.4,0.25$, and $0.17(\%)$ respectively. This prevalence was obtained on the basis of the diseased cases. Age and breed had a significant effect on the distribution of digestive problems in dogs $(p<0.001)$. Gender had an effect on the distribution of digestive problems with significant $(\mathrm{p} \leq 0.01)$ while season had a non-significant effect $(\mathrm{p}>0.05)$ on the distribution of such problems.
\end{abstract}

Conclusion: Digestive problems were the highest recorded problems among dogs, and this was the first records for such problems among dogs in Egypt. Age, gender, and breeds had a significant effect on the distribution of the digestive problems in dogs while season had a non-significant effect on the distribution of such problems. The present data enable veterinarians in Egypt to ascertain their needs for diagnostic tools and medication that must be present at any pet clinic.

Key words: canine, causes, digestive problems, Egypt, prevalence.

\section{Introduction}

Dogs are the most successful canids that were kept as pets by many people all over the world irrespective of their social status and most of these dogs were kept as watch, companion animals, and as a guide to handicapped persons. It also had been used in search and as a rescue dogs by police or armed forces [1]. Healthy digestive organs underpin the function of the whole digestive system through digestion and absorption of the nutrients, neutralization of the toxins and elimination of the wastes and unwanted products. The main problem for the majority of gastrointestinal diseases in dogs was that of clinical signs which may include vomiting, diarrhea and weight loss which shared by many conditions that have either primary or secondary effect on the

Copyright: The authors. This article is an open access article licensed under the terms of the Creative Commons Attributin License (http:// creative commons.org/licenses/by/2.0) which permits unrestricted use, distribution and reproduction in any medium, provided the work is properly cited. gastrointestinal tract [2]. For these facts, gastrointestinal disorders in dogs were considered as one of the most common and important cause of presentation to clinicians $[3,4]$. Vomiting and diarrhea were considered as a ways of discharging offending materials and toxins from the digestive system [5]. Although the higher occurrence of digestive problems among dogs in Egypt, limitation of the data about the prevalence of such problems was present, and the needs for diagnostic tools and emergency medications in clinics were still unclear.

The main object of this study was to determine the prevalence of the most common digestive problems compared with other health problems in dogs that were admitted to the teaching veterinary hospital, department of internal medicine and infectious diseases, faculty of veterinary medicine, Cairo University from January to December 2013. Also, determination of the main causes and the effect of age, sex, breeds, and season on the distribution of digestive problems in dogs. 


\section{Materials and Methods}

\section{Ethical approval}

The research procedures were approved by the department of internal medicine and infectious diseases, faculty of veterinary medicine, Cairo University, Egypt.

\section{Study area}

The dogs used for this study were those admitted to the teaching veterinary hospital, faculty of veterinary medicine, Cairo University, Giza, Egypt during the 1 year study period from January to December 2013

\section{Animals in the study}

A total of 3864 dogs (included 2358 males and 1506 females) which belonging to different ages and breeds were included in this study. This number included 2376 diseased dogs (included 1542 males and 834 females), and 1488 apparently healthy dogs (included 816 males and 672 females) which admitted either for vaccination or for general health checkup.

\section{Clinical examination}

All the cases were firstly registered in the registration book for date, age, sex, breed, and complaint of their owners. Detailed clinical examination of each patient was carried out including complete medical, vaccination, dietary, and environmental history. Visual inspection was done, and pulse, respiration rates, and rectal temperature were carefully taken. Also, examination of the different organs and body systems was performed [6].

\section{Other diagnostic tools}

Radiographic examination was applied according to Burk and Feeney [7] using X-ray machine (Fisher imaging $^{\circledR}$, with X-ray tube EMERALD-125, A-045211, Chicago, U.S.A.). Ultrasonography was applied according to Kealy and McAllister [8] using ultrasonographic device (Pie medical ${ }^{\circledR}$ scanner, Maastricht, Netherlandswith macro and micro convex sector transducers 3.5-5 and 5-7.5 MHz). Gastrointestinal endoscopy was applied according to Tams and Rawlings [9] using flexible endoscope (Fujinon ${ }^{\circledR}$ BRO-YP2 Japan) with an endoscopic camera (Lemke ${ }^{\circledR}$ MC 204) for both esophagogastroduodenoscopy and colonoscopy.

\section{Fecal analysis}

Fecal sample of each case was collected and examined immediately during the examination. Gross appearance, direct smear, and floatation technique were applied for the presence of adult worms, parasitic eggs and protozoal oocyst [10]. Fecal swabs from diarrheic dogs suffered from canine parvovirus infection, and corneal, nasal swabs from dogs with canine distemper virus infection were subjected to rapid antigen test kits. The presence of two color bands (test and control) within the result window indicated a positive result.

\section{Statistical analysis}

Data that were collected about age, sex, breed, and season were recorded and to Microsoft Excel 2010 ${ }^{\circledR}$ spreadsheet, stored separately and exported to analytical software using Chi-square test. Values of $\mathrm{p} \leq 0.05$ were considered as statistically significant.

\section{Results}

In the present study, the total number of examined animals was 3864. Out of this number, 2376 animals were diseased, and 1488 animals were apparently healthy representing $61.4 \%$ and $38.5 \%$ respectively. Diseased animals were divided into cases suffering from digestive problems (1344) and other health problems (1032) representing $56.5 \%$ and $43.4 \%$ out of diseased animals and $34.8 \%$ and $26.7 \%$ out of total examined animals respectively. The apparently healthy animals were 1488 which included 954 vaccinated and 534 non-vaccinated dogs representing 64.1\% and $35.8 \%$ respectively (Table- 1 ). The study showed that there was a five most common occurred digestive problems in dogs included vomiting, diarrhea, concurrent vomiting with diarrhea, anorexia, and constipation in $324,456,240,312$, and 12 cases respectively with diseased cases based prevalence of $(13.6 \%),(19.1 \%)$, $(10.1 \%),(13.1 \%)$, and $(0.5 \%)$ respectively (Figure- 1$)$. Other health problems were included dermatological, respiratory, urinary, neurological, cardiovascular, auditory, and ocular problems and recorded in 662 , $250,80,20,10,6$, and 4 cases respectively with diseased number based prevalence of $(27.9 \%),(10.5 \%)$, $(3.3 \%),(0.84 \%),(0.4 \%),(0.25 \%)$, and $(0.17 \%)$ respectively (Table-2). Regarding the type of feed, historical information revealed that owners offered both commercial dry feed (high or low-quality grade) and homemade diet that were offered all the day. In the present study, 260 cases showed food indiscretion included 185 cases were fed on homemade diets and 75 cases were fed on low grade commercial dry food

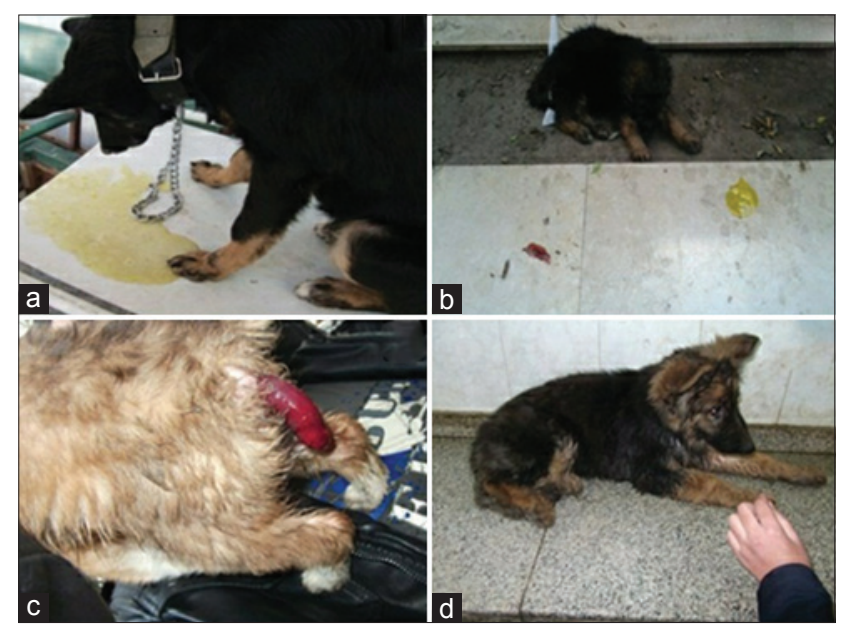

Figure-1: The clinical picture of different digestive problems. (a) Vomiting in 5 month old German Shepherd. (b) German Shepherd puppy suffered from concurrent vomiting with diarrhea as a result of Parvoviral infection. (c) Intestinal intussusception in 3 months old Griffon puppy. (d) 4 months old German Shepherd puppy suffered from generalized weakness, anorexia and dehydration as a result of diarrhea. 
Table-1: The prevalence of digestive problems versus other problems through 1 year period from January to December 2013.

\begin{tabular}{llccccc}
\hline Group & Sub-group & No. of & & \multicolumn{3}{c}{ Prevalence from (\%) } \\
\cline { 5 - 6 } & & dogs & Diseased group & Apparently Healthy group & Total number \\
\hline Diseased & Digestive problems & 1344 & 56.5 & - & 34.8 \\
& Other health problems & 1032 & 43.4 & - & 26.7 \\
Total & - & 2376 & - & 64.1 & 61.4 \\
Apparently & Vaccinated dogs & 954 & - & 35.8 & 24.7 \\
Healthy & Non-vaccinated dogs & 534 & - & - & 3.8 \\
Total & - & 1488 & - & 100 & 100 \\
Total & - & 3864 & 100 & & -5 \\
\hline
\end{tabular}

Table-2: Common digestive and other health problems in dogs admitted through 1 year period from January to December 2013.

\begin{tabular}{|c|c|c|c|c|c|}
\hline \multirow[t]{2}{*}{ Problem } & \multirow{2}{*}{$\begin{array}{l}\text { No. of } \\
\text { cases }\end{array}$} & \multicolumn{4}{|c|}{ Prevalence $(\%)$ toward } \\
\hline & & Digestive group & Other problems group & Diseased cases & Total no. (3864) \\
\hline \multicolumn{6}{|l|}{ Digestive problems } \\
\hline Vomiting & 324 & 24.1 & - & 13.6 & 8.3 \\
\hline Diarrhea & 456 & 33.9 & - & 19.1 & 11.8 \\
\hline Vomiting and Diarrhea & 240 & 17.8 & - & 10.1 & 6.2 \\
\hline Anorexia & 312 & 23.2 & - & 13.1 & 8 \\
\hline Constipation & 12 & 0.89 & - & 0.5 & 0.3 \\
\hline Total & 1344 & & & & \\
\hline \multicolumn{6}{|l|}{ Other problems } \\
\hline Dermatological & 662 & - & 64.1 & 27.9 & 17.1 \\
\hline Respiratory & 250 & - & 24.2 & 10.5 & 6.4 \\
\hline Urinary & 80 & - & 7.7 & 3.3 & 2.1 \\
\hline Neurological & 20 & - & 1.9 & 0.84 & 0.52 \\
\hline Cardiovascular & 10 & - & 0.96 & 0.4 & 0.25 \\
\hline Ear problems & 6 & - & 0.58 & 0.25 & 0.15 \\
\hline Ocular & 4 & - & 0.39 & 0.17 & 0.1 \\
\hline Total & 1032 & & & & \\
\hline Diseased cases & 2376 & - & - & - & - \\
\hline
\end{tabular}

(Table-3). The major cause of vomiting in the present study was the ingestion of foreign bodies which included chicken bones and fish hooks and this condition was noted in 112 cases and the recorded prevalence was $4.7 \%$ from the total diseased cases. Toward diarrhea and concurrent vomiting with diarrhea, the main cause was Parvoviral infection that recorded in 97 and 75 cases respectively with diseased cases based prevalence of $4 \%$ and $3.15 \%$ respectively. Food indiscretion was the most common cause for anorexia that recorded in 144 cases in the present study $(6.1 \%$ from diseased cases). In terms of constipation, the most recorded cause was ingestion of foreign bodies and anal sacculitis in 4 cases for each condition with diseased cases based prevalence of $0.16 \%$ for each cause (Table-3). The present study showed a significant effect $(p<0.001)$ of age on the occurrence of digestive problems as the puppies up to 6 months of age were more prone to diarrhea than other ages while dogs ranged from 6 months up to 3 years were more prone to anorexia. Older dogs showed an increase in the occurrence of vomiting than other digestive problems (Table-4). Gender had a significant effect $(\mathrm{p} \leq 0.01)$ on the occurrence of digestive problems as males were found to be more affected with diarrhea, vomiting, and concurrent vomiting with diarrhea while females were more prone to anorexia and constipation
(Table-5). In terms of breed, there was a significant effect $(p<0.001)$ on the occurrence of digestive problems as vomiting was of higher prevalence in giant and small breeds (Mastiff, Saint Bernard, Great Dane, and Caucasian) and (Griffon, Bug, and Pekingese) respectively. In large breed dogs (German Shepherd, Rottweiler, and Golden Retriever), diarrhea was the most prevalent problem while in medium breed dogs (Pit Bull, Labrador Retriever, and Boxer), anorexia was the most prevalent (Table-6). Season had a non-significant effect $(p>0.05)$ on the distribution of digestive problems among dogs (Table-7). Regarding the diagnostic tools required for definitive diagnosis in the present study, radiographic examination was carried out on 209 cases included 169 cases with foreign bodies, 30 cases with chronic constipation, and 10 cases suffered from renal stones (Figure-2). Ultrasonographic examination was carried out on 236 cases included enteritis, liver diseases, IBD, biliary sludge, renal diseases, pancreatitis, benign prostatic hyperplasia, and intestinal intussusception in $150,40,19,17,3,3,2$, and 2 cases respectively (Figure-3). Gastrointestinal endoscopy was performed on 64 cases included 34 cases with foreign bodies, 20 cases with intestinal parasites, and 10 cases with IBD (Figure-4). Rapid tests for detection of parvovirus and canine distemper virus were performed on 
Table-3: The prevalence of the common causes of digestive problems in dogs.

\begin{tabular}{|c|c|c|c|c|c|c|}
\hline \multirow[t]{2}{*}{ Problem } & \multirow[t]{2}{*}{ Causes } & \multirow[t]{2}{*}{ No. } & \multicolumn{4}{|c|}{ Prevalence $(\%)$ on the basis of } \\
\hline & & & $\begin{array}{l}\text { Problem } \\
\text { cases }\end{array}$ & $\begin{array}{c}\text { Digestive } \\
\text { diseased cases }\end{array}$ & $\begin{array}{l}\text { Diseased } \\
\text { cases }\end{array}$ & $\begin{array}{c}\text { Total } \\
\text { number }\end{array}$ \\
\hline \multirow[t]{10}{*}{ Vomiting } & Foreign body & 112 & 34.5 & 8.3 & 4.7 & 2.8 \\
\hline & Food indiscretion & 60 & 18.5 & 4.4 & 2.5 & 1.5 \\
\hline & Drugs (NSAIDs) & 40 & 12.3 & 2.9 & 1.68 & 1.03 \\
\hline & Pneumonia & 35 & 10.8 & 2.6 & 1.47 & 0.9 \\
\hline & Liver diseases & 30 & 9.2 & 2.2 & 1.26 & 0.77 \\
\hline & Poisoning & 15 & 4.6 & 1.1 & 0.63 & 0.38 \\
\hline & Biliary sludge & 10 & 3 & 0.74 & 0.42 & 0.25 \\
\hline & Motion sickness & 10 & 3 & 0.74 & 0.42 & 0.25 \\
\hline & IBD & 9 & 2.7 & 0.66 & 0.37 & 0.23 \\
\hline & Renal diseases & 3 & 0.9 & 0.22 & 0.12 & 0.07 \\
\hline \multirow[t]{9}{*}{ Diarrhea } & Parvoviral infection & 97 & 21.3 & 7.2 & 4 & 2.51 \\
\hline & Toxocara spp. & 95 & 20.8 & 7.1 & 3.9 & 2.4 \\
\hline & Dipylidium caninum & 80 & 17.5 & 5.9 & 3.3 & 2 \\
\hline & Food indiscretion & 46 & 10.1 & 3.4 & 1.93 & 1.19 \\
\hline & Taenia spp. & 41 & 8.9 & 3 & 1.72 & 1.06 \\
\hline & Ancylostoma spp. & 35 & 7.6 & 2.6 & 1.47 & 0.9 \\
\hline & Isospora spp. & 30 & 6.5 & 2.2 & 1.26 & 0.77 \\
\hline & Corona viral infection & 22 & 4.8 & 1.6 & 0.92 & 0.56 \\
\hline & IBD & 10 & 2.1 & 0.74 & 0.42 & 0.25 \\
\hline \multirow[t]{8}{*}{ Concurrent vomiting with diarrhea } & Parvoviral infection & 75 & 31.3 & 5.5 & 3.15 & 1.94 \\
\hline & Canine distemper & 60 & 25 & 4.4 & 2.52 & 1.55 \\
\hline & Foreign body & 53 & 22 & 3.9 & 2.23 & 1.37 \\
\hline & Toxocara spp. & 22 & 9.1 & 1.6 & 0.92 & 0.56 \\
\hline & Food indiscretion & 10 & 4.1 & 0.74 & 0.42 & 0.25 \\
\hline & Liver disease & 10 & 4.1 & 0.74 & 0.42 & 0.25 \\
\hline & Biliary sludge & 7 & 2.9 & 0.52 & 0.29 & 0.18 \\
\hline & Pancreatitis & 3 & 1.25 & 0.2 & 0.12 & 0.07 \\
\hline \multirow[t]{4}{*}{ Anorexia } & Food indiscretion & 144 & 46.1 & 10.7 & 6.1 & 3.72 \\
\hline & Oral lesions & 120 & 38.4 & 8.9 & 5.1 & 3.11 \\
\hline & During estrus cycle (Females) & 28 & 8.9 & 2.1 & 1.17 & 0.72 \\
\hline & Pharyngitis & 20 & 6.4 & 1.4 & 0.84 & 0.51 \\
\hline \multirow{4}{*}{ Constipation } & Anal sacculitis & 4 & 33.3 & 0.29 & 0.16 & 0.10 \\
\hline & Foreign body & 4 & 33.3 & 0.29 & 0.16 & 0.10 \\
\hline & Benign prostatic hyperplasia & 2 & 16.6 & 0.14 & 0.08 & 0.05 \\
\hline & Intestinal intussusception & 2 & 16.6 & 0.14 & 0.08 & 0.05 \\
\hline
\end{tabular}

Table-4: Age-wise prevalence of most common digestive problems in dogs.

\begin{tabular}{|c|c|c|c|c|c|c|c|c|}
\hline \multirow[t]{2}{*}{ Problem } & \multicolumn{6}{|c|}{ Age (\%) } & \multirow[t]{2}{*}{ p-value } & \multirow[t]{2}{*}{ Chi-square } \\
\hline & 1-3 months & 3-6 months & 6-12 months & 12-36 months & >36 months & Total & & \\
\hline Vomiting & 192 (27.9) & $12(7.3)$ & $24(11.6)$ & $60(28.9)$ & $36(45)$ & 324 & $0.00001 * * *$ & 263.31 \\
\hline Diarrhea & $264(38.5)$ & $96(58.5)$ & $48(23.2)$ & $24(11.6)$ & $24(30)$ & 456 & & \\
\hline $\begin{array}{l}\text { Vomiting } \\
\text { with diarrhea }\end{array}$ & $132(19.2)$ & $24(14.6)$ & $24(11.6)$ & $48(23.2)$ & $12(15)$ & 240 & & \\
\hline Anorexia & 96 (13.9) & $30(18.3)$ & $108(52.2)$ & $72(34.8)$ & $6(7.5)$ & 312 & & \\
\hline Constipation & $2(0.29)$ & $2(1.2)$ & $3(1.5)$ & $3(1.5)$ & $2(2.5)$ & 12 & & \\
\hline Total & 686 & 164 & 207 & 207 & 80 & 1344 & & \\
\hline
\end{tabular}

$* * * \mathrm{p}<0.001$ (significant)

Table-5: Sex-wise prevalence of most common digestive problems in dogs.

\begin{tabular}{lccccc}
\hline Problem & \multicolumn{3}{c}{ Sex } & \\
\cline { 2 - 6 } & Males (\%) & Females (\%) & Total & p-value & Chi-square \\
\hline Vomiting & $228(26.2)$ & $96(20.3)$ & 324 & $0.012 * *$ & 12.65 \\
Diarrhea & $300(34.5)$ & $156(32.9)$ & 456 & & \\
Vomiting with diarrhea & $156(17.9)$ & $84(17.7)$ & 240 & & \\
Anorexia & $180(20.7)$ & $132(27.8)$ & 312 & & \\
Constipation & $6(0.69)$ & $6(1.3)$ & 12 & & \\
Total & 870 & 474 & 1344 & & \\
\hline
\end{tabular}

$* * \mathrm{p} \leq 0.01$ (significant)

412 cases. Out of them, 232 cases showed a positive result that included 172 cases for parvovirus infection and 60 cases for canine distemper viral infection. Fecal analysis showed some parasitic infections included 
Table-6: Breed-wise prevalence of most common digestive problems in dogs.

\begin{tabular}{|c|c|c|c|c|c|c|c|c|}
\hline \multirow{2}{*}{ Breeds } & \multicolumn{6}{|c|}{ Problems } & \multirow[t]{2}{*}{ p-value } & \multirow[t]{2}{*}{ Chi-square } \\
\hline & Vomiting & Diarrhea & $\begin{array}{c}\text { Vomiting } \\
\text { and } \\
\text { Diarrhea }\end{array}$ & Anorexia & Constipation & Total & & \\
\hline Giant breed dogs & & & & & & & $0.00001 * * *$ & 122.74 \\
\hline Mastiff & 15 & 12 & 3 & 13 & - & 43 & & \\
\hline Saint Bernard & 3 & 5 & 2 & 5 & - & 15 & & \\
\hline Great Dane & 17 & 12 & 18 & 9 & 1 & 57 & & \\
\hline Caucasian & 2 & 4 & 5 & 5 & - & 16 & & \\
\hline Total (\%) & $37(28.2)$ & $33(25.2)$ & $28(21.4)$ & $32(24.4)$ & $1(0.76)$ & $131(100)$ & & \\
\hline \multicolumn{9}{|l|}{ Large breed dogs } \\
\hline German Shepherd & 96 & 276 & 132 & 96 & 5 & 605 & & \\
\hline Rottweiler & 30 & 36 & 24 & 20 & 2 & 104 & & \\
\hline Golden Retriever & 24 & 10 & 20 & 12 & 1 & 67 & & \\
\hline Black Coat & 12 & 20 & 10 & 40 & 1 & 83 & & \\
\hline Total (\%) & $162(18.6)$ & $342(39.5)$ & $186(21.5)$ & $168(19.4)$ & $9(1)$ & $867(100)$ & & \\
\hline \multicolumn{9}{|c|}{ Medium breed dogs } \\
\hline Pit Bull & 48 & 30 & 10 & 48 & 1 & 137 & & \\
\hline Boxer & 20 & 20 & 5 & 24 & - & 69 & & \\
\hline Labrador Retriever & 12 & 3 & 6 & 24 & - & 45 & & \\
\hline Doberman & 6 & - & - & - & - & 6 & & \\
\hline Dalmatian & - & 5 & - & - & - & 5 & & \\
\hline Mixed Breeds & - & - & - & 4 & - & 1 & & \\
\hline Total $(\%)$ & $86(32.3)$ & $58(21.8)$ & $21(7.9)$ & $100(37.6)$ & $1(0.38)$ & $266(100)$ & & \\
\hline \multicolumn{9}{|l|}{ Small breed dogs } \\
\hline Griffon & 33 & 21 & 5 & 12 & 1 & 72 & & \\
\hline Bug & 5 & 1 & - & - & - & 6 & & \\
\hline Pekingese & 1 & 1 & - & - & - & 2 & & \\
\hline Total (\%) & $39(48.8)$ & $23(28.8)$ & $5(6.3)$ & $12(15)$ & $1(1.3)$ & $80(100)$ & & \\
\hline Total & 324 & 456 & 240 & 312 & 12 & 1344 & & \\
\hline
\end{tabular}

$* * * \mathrm{p}<0.001$ (significant)

Table-7: Season-wise prevalence of most common digestive problems in dogs.

\begin{tabular}{lcccccc}
\hline Problems & \multicolumn{3}{c}{ Season } & \multirow{2}{*}{ p-value Chi-square } \\
\cline { 2 - 5 } & Winter (\%) & Spring (\%) & Summer (\%) & Autumn (\%) & Total & \\
\hline Vomiting & $64(24.8)$ & $70(20.5 \%)$ & $120(27.2)$ & $70(23.1)$ & 324 & 0.123 \\
Diarrhea & $81(31.4)$ & $125(36.6)$ & $135(30.5)$ & $115(37.9)$ & 456 & 17.74 \\
Vomiting with diarrhea & $53(20.5)$ & $58(17)$ & $73(16.5)$ & $56(18.5)$ & 240 & \\
Anorexia & $55(21.3)$ & $86(25.2)$ & $112(25.3)$ & $59(19.5)$ & 312 & \\
Constipation & $5(1.9)$ & $2(0.58)$ & $2(0.45)$ & $3(0.99)$ & 12 & \\
Total & 258 & 341 & 442 & 303 & 1344 & \\
\hline
\end{tabular}

p $>0.05$ (Non-significant)

Toxocara canis, Dipyledium caninum, Ancylostoma spp., and Isospora spp. (Figure-5).

\section{Discussion}

The present study had given an overall idea about the prevalence of the most common occurred digestive problems compared with other problems among dogs which presented for the teaching animal hospital, Faculty of Veterinary Medicine, Cairo University during 1 year period from January to December 2013. The present work showed that digestive problems had a prevalence of $56.5 \%$ from the total diseased dogs. Similar findings were reported in a study in Turkey, and the recorded prevalence was 52\% [11]. Also, digestive problems had the first order during first observation between 1995 and 1997 in Kosice, Slovakia [12]. Other studies were disagreed with the finding in the present study [13-18]. This difference can be explained as there was a magnificent difference in geographical distribution and the period of the studies. Also, bad feeding management and the endemic nature of most infectious diseases in Egypt such as parvovirus, canine distemper virus infection, and internal parasites infections shared in the elevation of such prevalence. The recorded prevalence of vomiting in the present study was $13.6 \%$ from the diseased cases, and this finding was disagreed with Atsbaha et al. [18] who recorded a prevalence of $4.6 \%$ from diseased cases in Mekelle City, Ethiopia. This may be due to the differences in feeding management, type of feed (when contained bones), and owner's awareness toward the grade of feed stuff that introduced to their dogs [19]. Also, in some cases, food was subjected to environmental contamination if introduced one time per day making it more prone to be spoiled and decomposed. Another cause was 


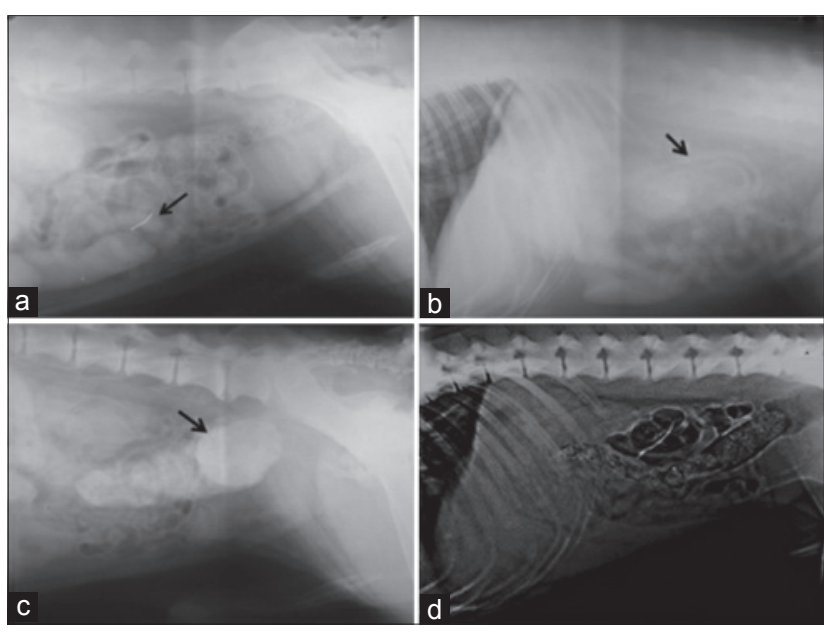

Figure-2: Left lateral radiographic views in some digestive problems among dogs. (a) Sharp foreign body inside the intestine of 8 months old German Shepherd. (b) Thickened intestinal loop due to enteritis in 1 year old Great Dane. (c) Radiopaque stool mass in the colon of 10 months old German Shepherd suffered from severe constipation. (d) Radiopaque pinpoint areas with gases formation inside the colon of 7 months old Rottweiler with signs of constipation and history of ingestion of chicken bones.

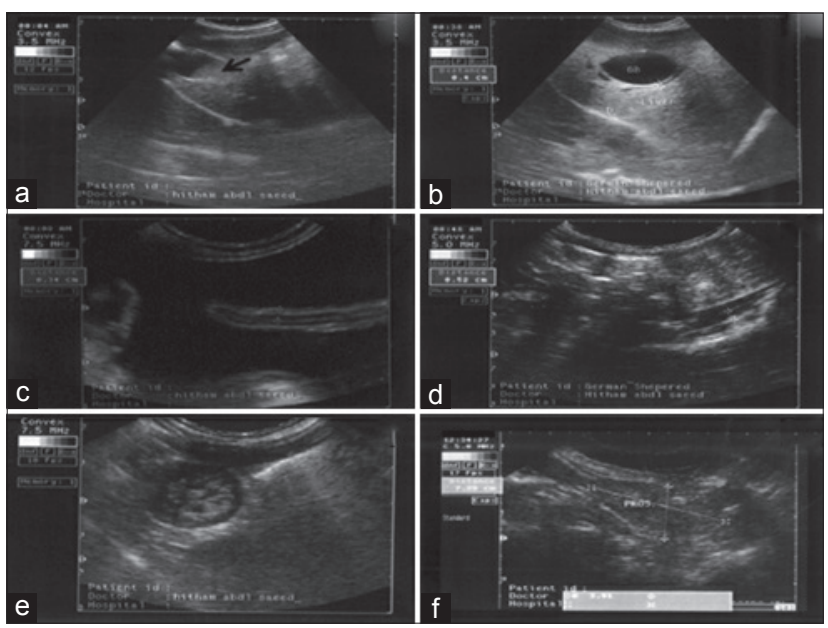

Figure-3: The ultrasonographic findings in dogs with different digestive problems. (a) Biliary sludge (arrow head) in 3 years old Pit Bull suffered from chronic vomiting. (b) Cholecystitis with edema between the two layers of gall bladder wall $(0.4 \mathrm{~cm})$ in 2 years old German Shepherd. (c) Free abdominal fluid (ascites) with presence of floating intestinal loop within fluid in 9 month old Pit Bull suffering from concurrent vomiting with diarrhea. (d) Thickened intestinal wall layers $(0.52 \mathrm{~cm})$ in 6 months old German Shepherd with diarrhea. (e) Characteristic view (Bull eye) of the intestinal intussusception in 3 months old Griffon suffered from severe obstipation. (f) 3 years old Rottweiler with severe constipation as a result of benign prostatic hyperplasia (measured $7.28 \times 3.91 \mathrm{~cm}$ ).

the abuse of anti-inflammatory drugs without any medical recommendation or adjustment of its doses was shared in increase the chance for gastritis and vomiting [20]. The main recorded cause of vomiting in the present work was the ingestion of foreign bodies (Table-3) and this finding was in accordance with Tams and Seim [21]. In agreement with the findings in the present study, diarrhea was the most often registered problem [22]. Several studies were recorded
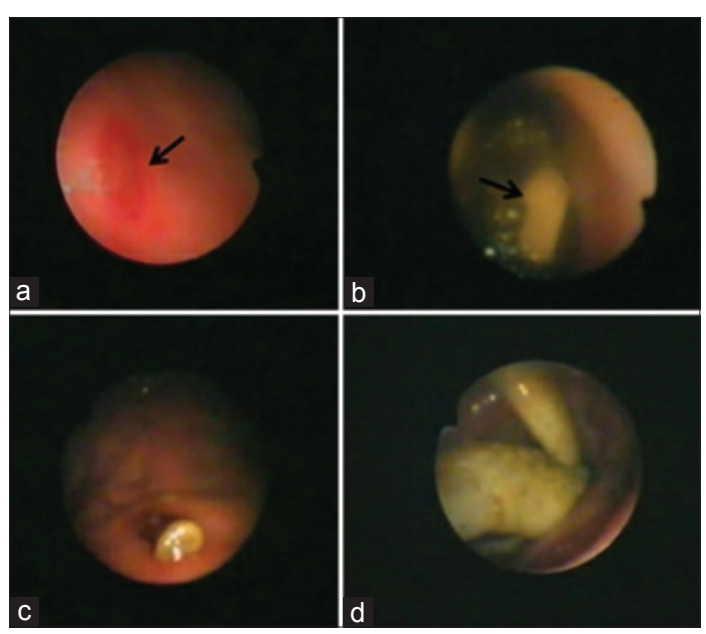

Figure-4: Showed the endoscopic findings of gastrointestinal problems in dogs. (a) Gastric ulcer (arrow head) showed a circumscribed area devoid of mucosa with congestion in 5 years old German Shepherd subjected to prolonged treatment with NSAIDs. (b) Dipylidium caninum adult worm within colon (arrow head) in 4-month-old Rottweiler suffered from flea's infestation and diarrhea. (c) An embedded foreign body in the gastric mucosa of 1-year-old Pit Bull. (d) Colonoscopy showed chicken legs and bones within the colon of 6 months old Golden Retriever suffered from severe constipation and intermittent vomiting.

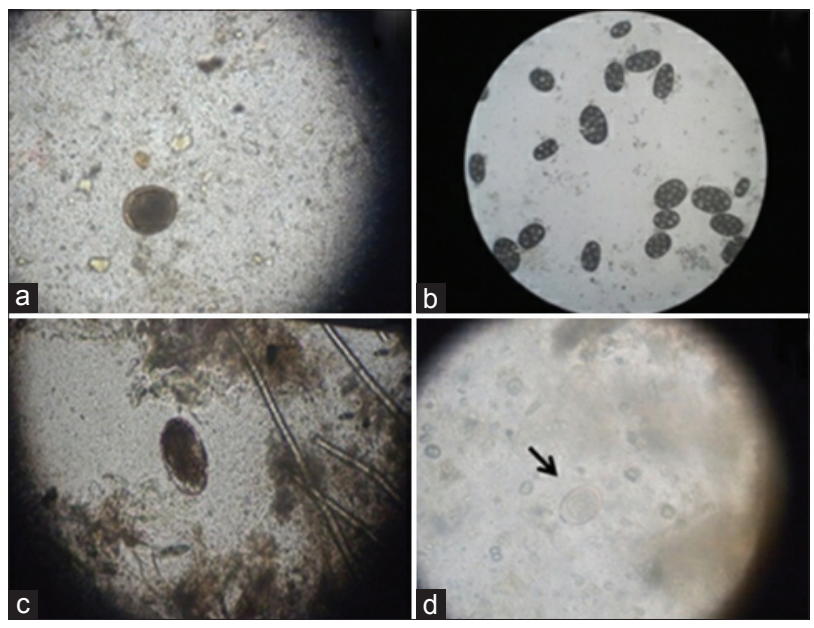

Figure-5: The different diagnosed parasitic eggs and oocysts in the stool of dogs suffered from digestive problems. (a) Toxocara canis egg $(\times 100)$. (b) The egg nest of Dipylidium caninum $(\times 100)$. (c) Ancylostoma spp. egg $(\times 100)$. (d) Isospora spp. oocysts $(\times 400)$.

a similar prevalence in the present study $[1,18,23]$. The recorded prevalence of concurrent vomiting with diarrhea in the present study was $10.1 \%$ from the diseased cases, and this result was agreed with Atsbaha et al. [18] who recorded a prevalence of $9.1 \%$ in a study in Mekelle City, Ethiopia. This could prove that there was a positive association between the occurrence of both diarrhea and vomiting in the same dog while the episodes of both problems didn't occur at the same time [4]. The most common cause of diarrhea, and concurrent vomiting with diarrhea was the Parvoviral infection, and this finding was agreed with Nappert et al. [24]. In terms of anorexia, the 
recorded prevalence was disagreed with that of Parvez et al. [25] and Chaudhari and Atsanda [26]. These differences can be explained as anorexia was the most common presented complaint for many diseases with wide variety of etiology and pathogenesis [27,28]. Constipation was of the lowest prevalence through digestive problems in the present work. This finding explained as constipation wasn't observed in dogs by many owners [29]. Another cause was that owners tend to treat this condition by traditional methods without resorting to veterinarian. Dermatological related cases were the second major health problems during the study period with recorded prevalence of $27.9 \%$ from total diseased cases. This result was in accordance with Jaffri and Rabbani [1] who recorded a prevalence of $22 \%$ for such condition in Lahore area, Pakistan while Atsbaha et al. [18] and Tarafder and Samad [23] were in disagreement with the study finding and recorded a prevalence of $38.5 \%$ and $37.12 \%$ respectively. This was attributed to the differences in the geographical distribution and the environmental temperature that controlling most populations of external parasites. The recorded prevalence of respiratory problems was close to that of Atsbaha et al. [18] and Yelmaz et al. [11] who recorded a prevalence of 13.8\% and $8 \%$ respectively from diseased cases in Ethiopia and Turkey respectively. Toward urinary problems, Jaffri and Rabbani [1] and Tarafder and Samad [23] recorded a prevalence of $1.27 \%$ and $5.15 \%$ from diseased cases respectively and these findings were close to that in the present work $3.3 \%$. Another study was disagreed with these findings and recorded this problem in $7.8 \%$ of diseases cases [11]. The remaining problems showed a lower prevalence as these conditions were slightly admitted to the clinic. The present study showed a significant effect $(p<0.001)$ of age on the occurrence of digestive problems in dogs. Similar studies demonstrated the same effect [22]. Some workers showed that diarrhea was of higher prevalence in puppies, and it was declined with increasing age $[30,31]$. This can be explained as the puppies were immunologically inactive and by 12 weeks of age, the majority lost their maternal immunity [32]. Another cause was that stress of weaning, rehoming, and transportation can lead to increase the susceptibility of such problem [33]. Anorexia was a prevalent problem in dogs ranged from 6 to 36 months of age in the present study. This result was attributed to the association between anorexia and many diseases with wide variation of etiology and pathogenesis [27,28]. In older ages (more than 36 months), vomiting was found to be the most prevalent problem in the present study. Most of old dogs were more susceptible to chronic diseases that shared by many clinical signs included vomiting [34]. Other studies reported no association between the age and frequency of gastrointestinal disorders [35]. In the present study a significant effect $(p \leq 0.01)$ of gender on the occurrence of the digestive problems was found and this finding was in agreement with another study as males were rendered at high risk for developing gastrointestinal disorders [22] especially for diarrhea $[35,36]$. This result explicated as males had increased sniffing and roaming behavior than females $[37,38]$. Also, males tend to inspect the head and anogenital areas of other dogs than females [39]. The present study showed that anorexia was more prevalent in females than males. Some workers also detected this result as the pregnancy had some complications that may lead to anorexia [40]. Another explanation was that female sex hormones were found to increase the risk of constipation in females [41]. Some workers were disagreed with these findings and concluded no effect [30,42]. In the present work, breed had a significant effect $(p<0.001)$ on the distribution of digestive problems in dogs. Similar study showed that the incidence of vomiting and diarrhea was significantly affected by breed $[22,35]$. German Shepherd had a higher prevalence of the gastrointestinal problems than other breeds [23] as there were either differences in genetic susceptibility, feeding regimens, behavior, and the type of feed $[22,43]$. Regarding season, the present study showed a non-significant effect $(p>0.05)$ of the season on the occurrence of digestive problems in dogs. This finding was in the line with another study showed that diarrhea was commonly detected throughout the year [3]. This can be explained as the symptoms may be seen throughout the year, but the causes for each problem were different. Some studies were disagreed with this finding [22].

\section{Conclusion}

It was the first recorded data about the prevalence of digestive problems and the other health problems for the cases that were admitted to the teaching veterinary hospital, faculty of veterinary medicine, Cairo University, Giza, Egypt during 2013. It was concluded that digestive problems considered as the major health problem among dogs. Age, sex, and breeds had a significant effect on the distribution of digestive problems while season had a non-significant effect on the distribution of such problems in dogs. Integration between diagnostic tools had an effective role in getting a rapid and accurate diagnosis of digestive problems. Medical awareness of the owners should be increased through the clinics toward the feed type (good, bad and toxic feed stuffs), feeding regimens, and quality of feed toward dogs. Great concern should be given to deworming and vaccination status of the dogs with observance the booster vaccination and periodical health checkup. The present data enable the veterinarians in Egypt to ascertain their needs for diagnostic tools and medication that must be present at any pet clinic.

\section{Authors' Contributions}

GMHR and MMAH designed the entire study. HAMF and HAS carried out all diagnostic procedures 
included clinical examination, fecal analysis, radiography, ultrasonography, and endoscopy. HAS recorded the prevalence along with analysis of data, finalized the manuscript for communication to the journal. All the authors read the manuscript and approved the final manuscript.

\section{Acknowledgments}

The authors are highly thankful to Department of Medicine and Surgery, Faculty of Veterinary Medicine, Cairo University, Egypt for providing support to carry out this study.

This study was fully self-funded.

\section{Competing Interests} interests.

The authors declare that they have no competing

\section{References}

1. Jafri, S.A. and Rabbani, M. (1999) Prevalence of canine disease in Lahore area. Pak. Vet. J., 19(1): 40-42.

2. Batt, R. (2009) Laboratory diagnosis of intestinal diseases in dogs and cats. Vet. Focus, 19(1): 10-19.

3. Malancus, R.N., Tofan, C. and Solcan, G. (2010) The use of ultrasonography in the diagnosis of gastrointestinal diseases in dogs. Vet. Med., 67(2): 143-149.

4. Armstrong, P.J. (2013) Gastrointestinal intervention: Approach to diagnosis and therapy of the patient with acute diarrhea. Today's Vet. Pract., 20-56.

5. Burns, J. (2012) The Veterinary Health \& Nutrition Handbook. $1^{\text {st }}$ ed. Burns Pet Nutrition Ltd., Carmathenshire. pp. 9-10.

6. Rijnberk, A. and Stokhof, A.A. (2009) General examination. In: Rijnberk A. and van Sluijs F.J. editors. Medical History and Physical Examination in Companion Animals. 2nd ed. Saunders Elsevier, China. pp. 47-62.

7. Burk, R.L. and Feeney D.A. (2003) The abdomen. In: Small Animal Radiology and Ultrasonography: A Diagnostic Atlas and Text. $3^{\text {rd }}$ ed. Saunders, Elsevier Science, U.S.A. pp. 249-251.

8. Kealy, J.K. and McAllister H. (2000) The abdomen. In: Diagnostic Radiology and Ultrasonography of Dog and Cat. $3^{\text {rd }}$ ed. W.B. Saunders, Philadelphia. pp. 31-87.

9. Tams, T.R. and Rawlings, C.A. (2011) Small Animal Endoscopy. $3^{\text {rd }}$ ed. Elsevier Mosby, U.S.A.

10. Zajak, A.M. and Conboy, G.A. (2012) Fecal examination for the diagnosis of parasitism. In: Veterinary Clinical Parasitology. $8^{\text {th }}$ ed. Wiley-Blackwell, UK. pp. 3-12.

11. Ylmaz, Z., Kennerman, E., Senturk, S., Temizel, M. and Aytug, N. (2002) The evaluation of cats and dogs referred to the clinics of companion animals-internal medicine, veterinary faculty, university of Uludag (1999-2000). Vet. Fakultesi Derg. Uludag Univ., 21(1/3): 23-31.

12. Kozak, M., Bilek, J., Fialkovicova, M., Neuschl, J. and Stratilova, M. (2001) The prevalence of dog diseases in the Kosice region in the period of 1998-2000. Folia Vet., 45(4): 44-48.

13. Harlette, M.J., Maxie, M.G., Allen, D.G. and Wilcock, B.P. (1983) A retrospective study of heart disease in Doberman pinscher dogs. Can. Vet. J., 24: 205-210.

14. Williams, D.L., Health, M.F. and Wallis, C. (2004) Prevalence of canine cataract: Preliminary results of a cross sectional study. Vet. Ophthalmol., 7: 29-35.

15. Freeman, L.M., Abood, S.K., Fascetti, A.J., Fleeman, L.M., Michel, K.E., Laflamme, D.P., Bauer, C., Kemp, B.L.E., Doren, J.R.V. and Willoughby, K.N. (2006) Disease prevalence among dogs and cats in the United States and Australia and proportions of dogs and cats that receive therapeutic diets or dietary supplements. J. Am. Vet. Med. Assoc., 229: 531-534.

16. Meler, E., Dunn, M. and Lecuyer, M. (2008) A retrospective study of canine persistent nasal disease: 80 cases (1998-2003). Can. Vet. J., 49: 71-76.

17. Kozak, M., Frey, T., Bilek, J., Goldirova, K. and Madari, A. (2008) Prevalence and screening of dog diseases in Kosice, Slovakia. Slov. Vet. Casopis, 33(2): 104-108.

18. Atsbaha, G., Hussien, D. and Cruz, R.C. (2014) Assesment of major health problems of dogs in Mekelle City, Ethiopia. Glob. Vet., 12(2): 176-180.

19. Kovalkovicova, N., Sutiakova, I., Pistl, J. and Sutiak, V. (2009) Some food toxic for pets. Interdiscip Toxicol, 2(3): 169-176.

20. Saravanan, M., Nagarajan, B., Kavitha, S., Balachandaran, C. and Srinivasan, S.R. (2012) Duodenoscopic apprasial of dudenal ulcer in dogs. Vet. World, 5(7): 420-423.

21. Tams, T. and Seim, H. (2013) Gastrointestinal foreign body obstruction in dogs. Western Vet. Conf. SA-290: 1-7.

22. Saevik, B.K., Skancke, E.M. and Trangerud, C. (2012) A longitudinal study on diarrhea and vomiting in young dogs of four large breeds. Acta Vet. Scand., 54: 8.

23. Tarafder, M. and Samad, M.A. (2010) Prevalence of clinical diseases of pet dogs and risk perception of zoonotic infection by dog owners in Bangladesh. Bangladesh J. Vet. Med., 8(2): 163-174.

24. Nappert, G., Dunphy, E., Ruben, D. and Mann, F.A. (2002) Determination of serum organic acids in puppies with naturally acquired Parvoviral enteritis. Can. J. Vet. Res., 66: $15-18$.

25. Parvez, A., Prodhan, A.M., Das, B.C. and Khatun, R. (2014) Prevalence of clinical conditions in dogs and cats at teaching veterinary hospital (TVH) in Chittagong veterinary and animal sciences university, Bangladesh. Res. J. Vet. Pract., 2(6): 99-104

26. Chaudhari, A.W.S. and Atsanda, N.N. (2002) Prevalence of some diseases of dogs and cats at the state government veterinary clinic in Maidugury, Nigeria. Pak. Vet. J., 22(2).

27. Delaney, S.J. (2006) Management of anorexia in dogs and cats. Veterinary clinics of North America. Small Anim. Pract., 36: 1243-1249.

28. Chan, D. (2009) The in appetent hospitalized cat. Clinical approach to maximizing nutritional support. J. Feline Med. Surg., 11: 925-933.

29. Gaskins, J. (2012) Constipation: The moving truth about a tough topic in pets. Am. Coll. Vet. Pharm., 15(4): 1-4.

30. Wells, D.L. and Hepper, P.G. (1999) Prevalence of disease in dogs purchased from an animal rescue shelter. Vet. Rec., 144: $35-38$

31. Castro, T.X., Uchoa, C.M.A., Albuquerque, M.C., Labarthe, N.V. and Garcia, R.C.N.C. (2007) Canine parvovirus $(\mathrm{CPV})$ and intestinal parasites: Laboratorial diagnosis and clinical signs from puppies with gastro-enteritis. Int. J. Appl. Res. Vet. Med., 5(2): 72.

32. Jarret, O. and Ramsey, I. (2001) Vaccination. In: Ramsey, I. and Gloucester, T.B., editors. Manual of Canine and Feline Infectious Diseases. British Small Animal Veterinary Association, UK. pp. 41-50.

33. Tennant, B. (2001) The alimentary tract. In: Ramsey, I. and Gloucester, T.B., editors. Manual of Canine and Feline Infectious Diseases. British Small Animal Veterinary Association, UK. pp. 129-150.

34. Viviano, K.R. (2011) Common geriatric diseases of cats. School of Veterinary Medicine, University of Wisconsin. Available from: http://www.invma.org. Accessed on 13-1-2012.

35. Hubbard, K., Skelly, B.J., Mckelvie, J. and Wood, J.L. (2007) Risk of vomiting and diarrhea in dogs. Vet. Rec., 161: 755-757.

36. Stavisky, J., Radford, A.D., Gaskell, R., Dawson, S., German, A., Parsons, B., Clegg, S., Newman, J. and Pinchbeck, G. (2011) A case control study of pathogen and 
lifestyle risk factors for diarrhea in dogs. Prev. Vet. Med., 99: 185-192.

37. Westgarth, C., Pinchbeck, G.L., Bradshaw, J.W.S., Dawson, S., Gaskell, R.M. and Christley, R.M. (2008) Doghuman and dog-dog interactions of 260 dog-owing household in a community in Cheshire. Vet. Rec., 162: 436-442.

38. Maarschalkerweerd, R.J., Endenburg, N., Kirpensteijn, J. and Knol, B.W. (1997) Influence of orchiectomy on canine behavior. Vet. Rec., 140: 617-619.

39. Bradshaw, J.W.S. and Lea, A.M. (1992) Dyadic interactions between domestic dogs. Anthrozoos, 5: 245-253.

40. Romagnoli, S., (2002) Complications in canine pregnancy and their clinical approach. Proceedings of the Veterinary Science Congress, SPCV, 10-12 Out. pp. 159-162.

41. Oh, J.E., Kim, Y.W., Park, S.Y. and Kim, J.Y. (2013) Estrogen rather than progesterone cause constipation in both female and male mice. Korean J. Physiol. Pharmacol., 17: 423-426.

42. Proschowsky, H.F., Rugbjerg, H. and Ersboll, A.K. (2003) Morbidity of purebred dogs in Denmark. Prev. Vet. Med., 58: 53-62.

43. Houston, D.M., Ribble, C.S. and Head, L.L. (1996) Risk factors associated with parvovirus enteritis in dogs: 283 cases (1982-1991). J. Am. Vet. Med., Assoc., 208: 542-546.

$* * * * * * * *$ 